\title{
Design and Implementation of a Collaborative Educational Gamification Authoring System
}

\author{
https://doi.org/10.3991/ijet.v16i17.24087 \\ Feng-Jung Liu( $\left.{ }^{\bowtie}\right)$, Chia-Mei Lu \\ Cheng-Shiu University, Kaohsiung, Taiwan \\ k3013egcloud.csu.edu.tw
}

\begin{abstract}
Gamification has been widely applied on modern education. Most of them are used to stimulate learning motivation and improve learning efficiency for students. A successful game-based learning content depends on both an adaptive educational activity planning and a high-quality game design. In educational activity planning, the $5 \mathrm{E}$ learning cycle model presents a framework for constructive learning theories and is effectively used in education sciences. Thus, in this study, a proposed collaborative educational gamification authoring system, CeGAS, is recommended to teachers to realize their gamebased learning/teaching planning activities based on the $5 \mathrm{E}$ learning cycle model. Using the CeGAS, rich experienced teachers could easily plan and conduct their educational activities without considering the complexity and difficulty of game implementation. As each experienced teacher follows the steps of the $5 \mathrm{E}$ learning cycle in the proposed script editing system, including engagement, exploration, explanation, elaboration, and evaluation, an available and exclusive game-based learning content with the 5E learning strategy will be developed. We are looking forward to achieving the goals of educational gamification with the educational game authoring system.
\end{abstract}

Keywords-authoring system, game-based learning system, education gamification

\section{Introduction}

Research have shown that the game-based learning and educational gamification have the potential to improve learning motivation and engagement and becomes one of important research domains. Some of them also reveal that digital games will be essential future teaching tools $[2,4,5]$. Therefore, developing useful digital learning games is worthy of investment. And, how to reduce the efforts of developing digital educational games is one of the important topics on game-based learning design $[7,8,15]$.

Successful education, besides rich experienced educators, also requires highquality learning contents and creative teaching planning. These requirements depend on rich experienced educators. How to integrate learning objectives and game missions is one of the most important issues in educational gamification to motivate stu- 
dents to continue studying. Additionally, it is another important topic that how to share and save the successful lesson plans of experienced teachers on the modern educational authoring system.

In this paper, we focus on the implementation and design of user-friendly educational game authoring system. The educational game authoring system based on the $5 \mathrm{E}$ learning cycle supports educators to easily edit educational game with storytelling. In Section 2, it describes the relative works, including $5 \mathrm{E}$ pedagogical model, game design considerations and relative authoring tools. In Section 3, it describes the system design and shows an example of playing educational game. In Section 4, it illustrates the contributions of the work and the experience questionnaire results.

\section{Related works}

\subsection{E learning cycle}

The 5E learning cycle was attributed to the Biological Sciences Curriculum Study (BSCS) which began adopting the instructional model in most of its programs in the late 1980s. Thus, that model is commonly referred to as the BSCS 5E instructional model. The 5E instructional model defines a learning sequence and presents a framework for constructive learning theories. It consists of the five phases: engagement, exploration, explanation, elaboration, and evaluation. Each phase has a specific function and contributes to the teacher's coherent instruction and the students' formulating a better understanding of scientific and technological knowledge, attitudes, and skills.

The summary of the five learning phases of the instructional model is described as the followings [1]:

- Engagement: These experiences mentally engage students with an event or question. Engagement activities helps students to make connections with what they know and can do. The goal is to spark students' interest and involvement.

- Exploration: In this phase, students to work with materials that give them a handson experience of the phenomena being observed. Under the guidance of the teacher or exploration activities, students experience a common set of experiences that helps them clarify their own understanding of major concepts and skills.

- Explanation: Students are asked to explain their understanding of the concepts and processes they are learning. And teachers help students clarify their understanding and introduce information related to the concepts to be learned.

- Elaboration: These elaboration activities challenge students to apply what they have learned and extend their knowledge and skills. During the elaboration phase, teachers encourage students to use what they have learned to explain a new event or idea and ask questions to help students draw reasonable conclusions using evidence and data from previous experiences.

- Evaluation: To find and measure whether learning objectives have been met and misconceptions avoided or not, evaluation should be on-going at all learning phases. Evaluation activities also allow teachers to evaluate students' progress toward 
achieving the educational objectives and induce students to assess their own knowledge, skills, and abilities.

\subsection{Design flow in games}

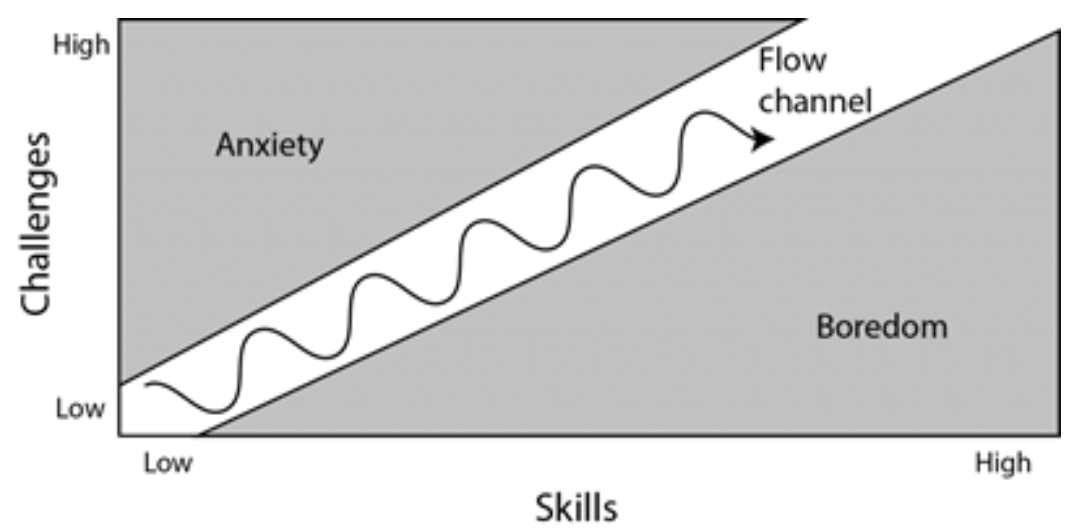

Fig. 1. Flow Channel Wave (from "The Art of Game Design" book by Jesse Schell)

To maintain a person's Flow experience, the activity needs to reach a balance between the challenges of the activity and the abilities of the participants [9]. A good game mechanism must ensure that the player runs smoothly in the virtual game world and can promote the player to toward to the designer's goal. Therefore, the design of the activity needs to keep a balance between the difficulty of the task and the abilities of the players to avoid players from getting stuck in anxious or bored state. Game mission is the core of game design, so all of design factors should be based on this. Above all, game designers should consider what kind of experience are provided to players. Diversified game types with different game mechanics can attract more people to participate. However, when the learner uses the game-based learning system, which one the focus on proficient game tasks or learning objectives will affect the learner's immersed state [10].

\subsection{Game authoring environment}

It is one of the most important educational gamification issues that how to combine the education and the game in the activities. Many reports present which game elements are suitable for educational gamification to increase user engagement in gamebased learning activities, including points, level, badges, leader board, and timers $[13,15]$. An educational game authoring tools are required to associate game missions with learning objectives. The player/learner is asked to accomplish learning missions to achieve game objectives. Generally, the objectives of the game are collaboratively negotiated by the teacher and the game designer to provide a list of educational elements, including fun, interactivity, problem-solving ability, user engagement or motivation and creativity, etc. [10]. 
SeGAE [11], Serious Game Authoring Environment, provides instructors a set of editors to define character characteristics, mission objectives, defeat and/or victory conditions and the authorized actions in each game mission. It mainly contains 4 different editors, including Character editor, temporal scenario editor, message and dialogue editor, and Game internationalization. The description of the adaptable game objects (characters, missions, etc.) are saved in the XML files. SeGAE generates the game missions corresponding to the instructor specifications and provides the teacher with the environment to possibly plan a serious game adapted to his pedagogical objectives.

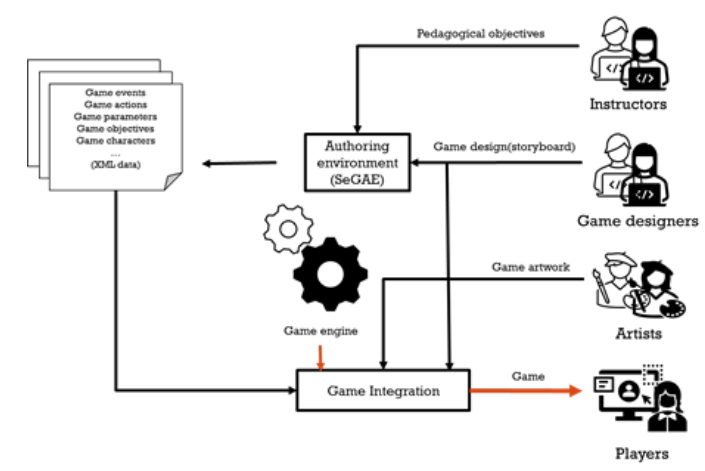

Fig. 2. Serious game Framework of SeGAE [11].

\section{CeGAS system design}

The CeGAS, the proposed collaborative educational game authoring system, is mainly used to achieve the game-based learning planning, which would reduce the difficulties, costs, efforts and time of game development. Related systematic principles of serious games and are also discussed in [14]. Through the collaboration and resource sharing, educators can fulfil their expectations of joyful learning and learning resources reuse. There are 5 collaborated roles in the CeGAS: Teachers, Students, Editors, Game Asset Designers, and Game Masters, as shown in Figure 3. The overview and game design methods of the CeGAS are described below. 


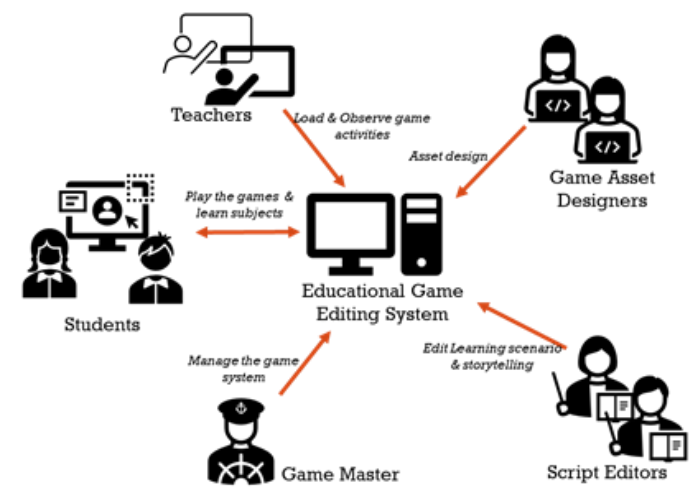

Fig. 3. System Overview of the CeGAS.

\subsection{The three-layered educational games design}

The CeGAS is to provide a consistent way of editing educational game scripts. A three-layer educational game editing design mode is proposed to establish a link between Learning Activities and Game Activities, as shown in Figure 4. Between learning activities and game activities, script editors achieve the goal of game-based learning with story scripting, material developing, and game designing. In material developing, it focuses on the combination with learning units and pedagogy.

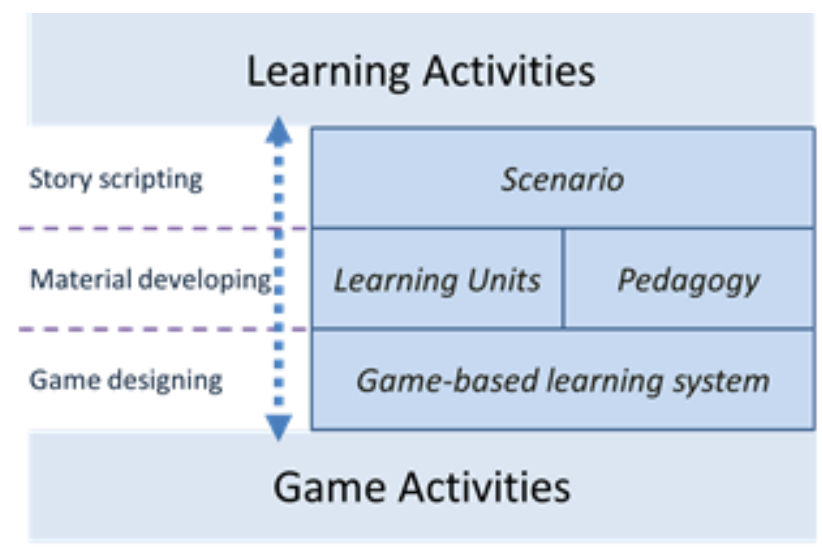

Fig. 4. The Concept of Three-Layered Scripting for Collaborative Educational Games Design.

To fulfil the game-based learning activities, it needs 5 collaborated roles, including teachers, learners, educational game script editors, smart game object (SGO) designers, and course manager/game master, as shown in Figure 5. Especially educational game script editors, they would have rich experiences on teaching practice and like to play as storytellers. by the NPCs in an educational game, the points of learning contents are elaborated to learners/students. 
The learning gamification script editing module facilitated their learning material scripting for educational game script editors, as shown in Figure 6. The experiential learning strategy based on the $5 \mathrm{E}$ learning cycle has been implemented in the proposed game editing system.

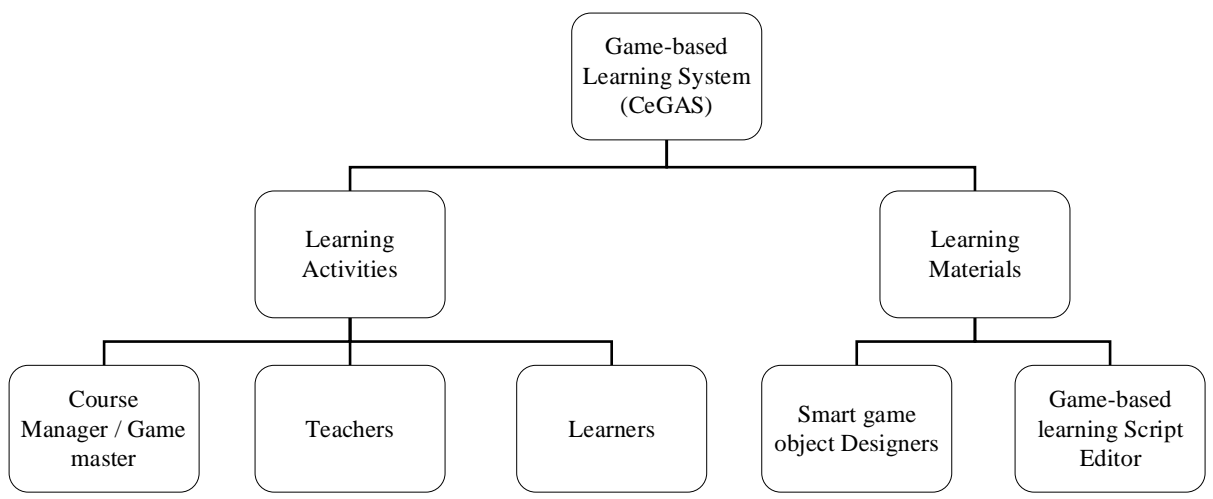

Fig. 5. Five Roles in the CeGAS Game-based Learning System.

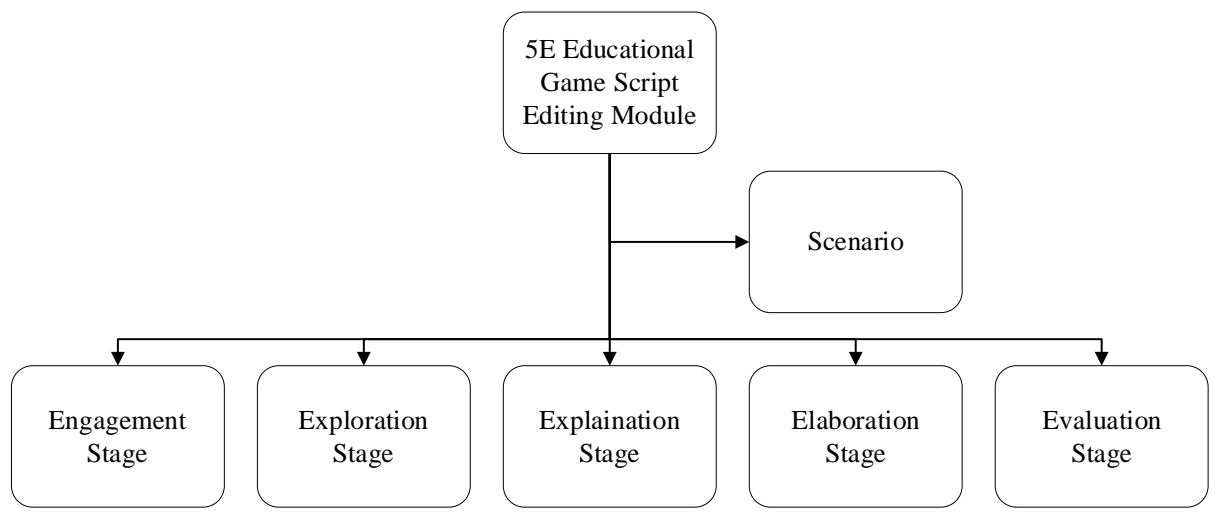

Fig. 6. Educational Game Script Editing Module with the 5E Learning Cycle.

1. Smart assets designers mainly design game objects conforming to the design principle of smart object of the editing system. The smart game objects are utilized as game script materials by the game-based learning script editor.

2. Educational game script editor is a scenario writer who is a storyteller and design the learning gamification activities based on the $5 \mathrm{E}$ learning cycle.

3. Additionally, teachers, learners, and game master/course manager are the main core roles in learning activities executions. However, For the space limitation and the focus on the design of the game-based learning editing system in the report, we omit these roles' missions and permissions. 
For each stage of the 5E learning model, the game-based learning script editors follow the game-based learning scenario to describe and to achieve the learning goals. The integration between game design and learning strategies mostly depends on the coordination of the experienced educators and scenario writers. The scenario writer could create characters according to the story plot. The CeGAS can describe the whole story and the learning objectives by the non-player character, NPC, deployment.

Combining storytelling with educational gamification, two kinds of NPCs are assigned with different missions in the CeGAS system. The one of NPCs plays as a storyteller who mainly tell the players the whole story along with the game levels; The other works as a level tutor who guides the player how to obtain the relevant knowledge and skills in this level.

\subsection{Flow in game design}

In the game design, it should serve players a much better game experience and keep them engaged in the game flow as shown in Figure 7. In this project, a third person fighting game is taken as a typical game. The difficulty of game level will increase along with the higher stages in the 5E cycle. In addition, the rewarding to the achievement of the players is adopted. For example, in the fighting game-playing, to increase defensive power, to recovery health, and to add the weapon will help a player be brave to face difficulties with less anxiety. To avoid the low sense of accomplishment in challenging the level of game, the reward content needs to be adaptable to the skills and difficulties of game levels [5].
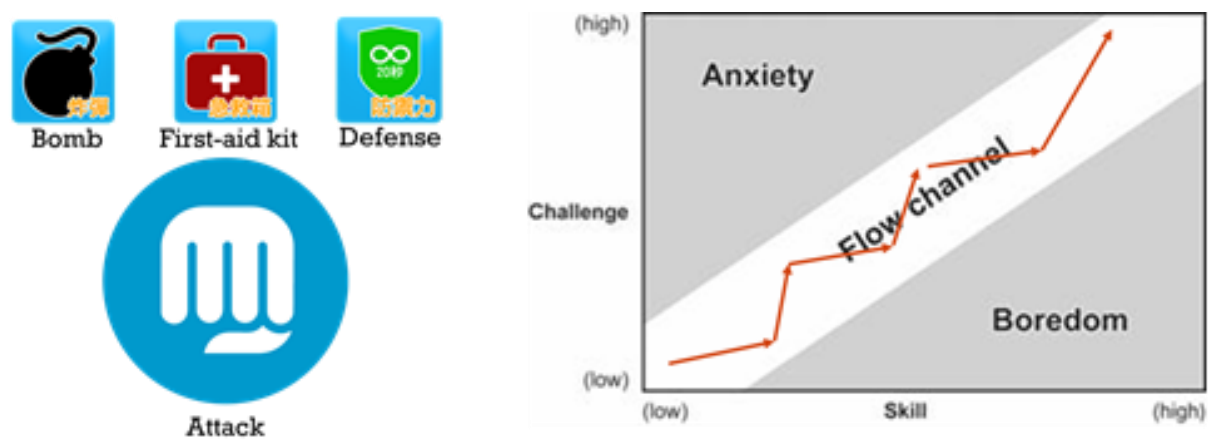

Fig. 7. The Flow Design in Game.

Currently, a third person fighting game is proposed as one of game types in the CeGAS system. But, in the framework of the CeGAS system, it may be practicable to extend other different types of games. 


\subsection{Smart asset editing}

An efficient educational material editing tools always provides editors with many types of assets for story scripting. In addition to native types of game objects, as sounds, icons, videos, pictures, it provides smart game objects, SGO, in the CeGAS system.

Smart assets are the collection of encapsulated game objects and are created and uploaded by asset designers. Smart assets are not only used to provide players with learning items, but also are used as the interface with the educational game learning system, as shown in Figure 8. There are many types of game objects in smart assets, including encapsulated scenes, encapsulated characters, smart NPCs, etc. Besides, these assets can be also packaged according to different stories for convenient retrievals of script editors and can effectively reduce the burden of educational script editing.
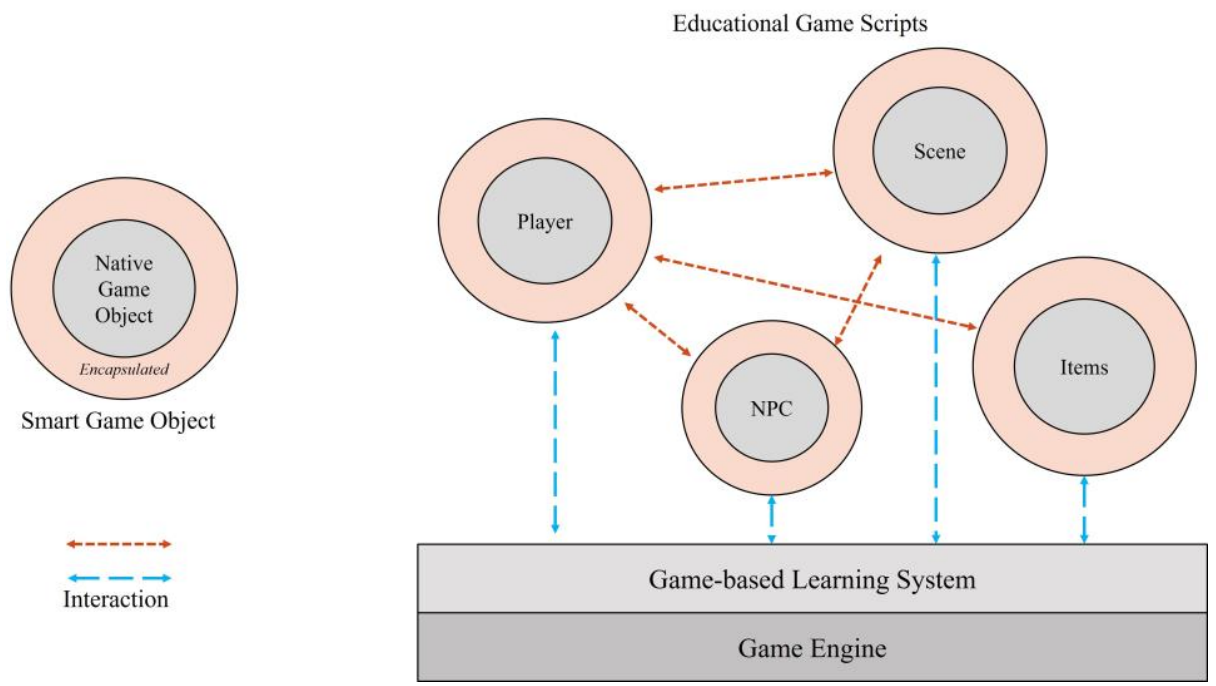

Fig. 8. Interactions of Smart Game Objects with CeCAS Game-based Learning System.

These pre-built SGOs are dynamically downloaded from the cloud database on the game script demands into the game-based learning system for the players. In the CeGAS implementation, an AssetBundle method [12] is used to the SGO creation. An Asset Bundle mechanism allows automatic updates and be reused. When new educational game scripts and SGOs are published respectively by script editors and asset designers, the last updated content could automatically be suggested to players and script editors without any application updates. 


\subsection{Learning game authoring using CeCAS}

Teachers are responsible for planning learning activities for different learning units. In the proposed CeCAS system, a teacher follows the 5E learning cycle strategy to plan their game-based learning sequences and design game levels in each stage according to the learning units. A case of learning game authoring by the CeCAS is presented as shown in Figure 9.

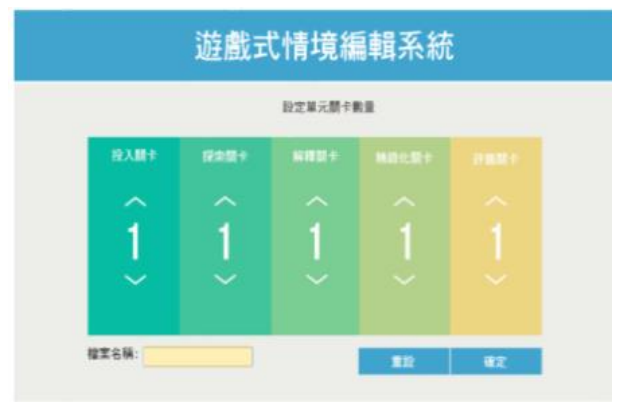

(a)

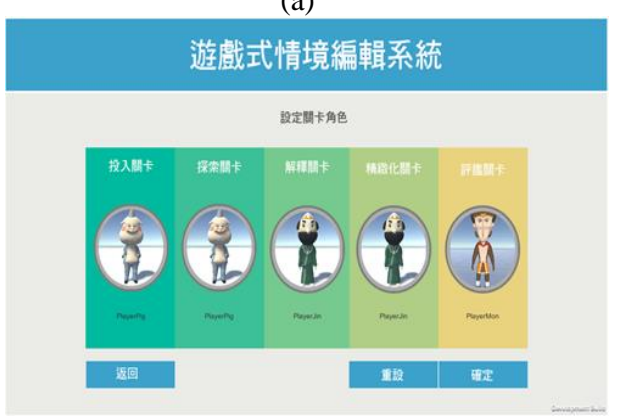

(c)

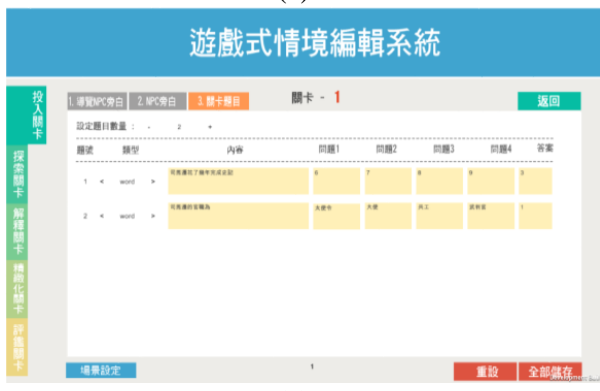

(e)

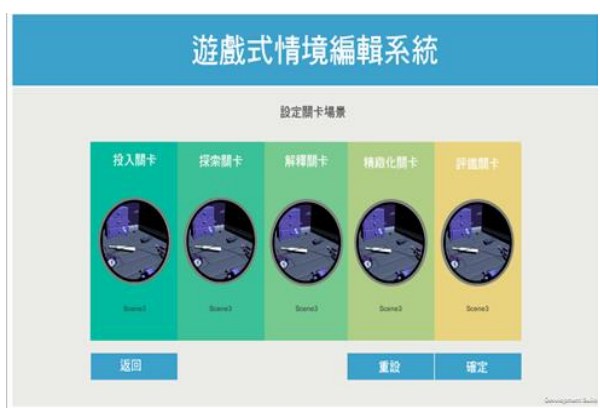

(b)

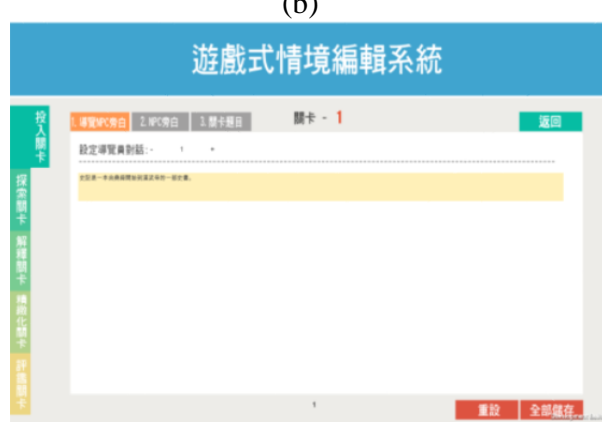

(d)

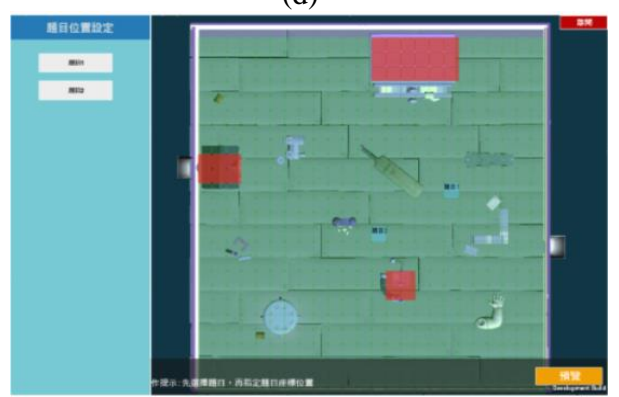

(f)

Fig. 9. (a)The settings of game level with the $5 \mathrm{E}$ learning cycle. (b)Choosing a scene from smart assets. (c) Selecting characters for each scene from assets. (d) Editing the narrations of NPCs. (e) Editing test items for each game level. (f) Setting test items in each game scene. 


\subsection{A case of educational game playing}

In the CeGAS system, students could find out these game-based learning materials while teachers finished their game-based learning scripts. The detailed operations of game-playing are shown in Figure 10.

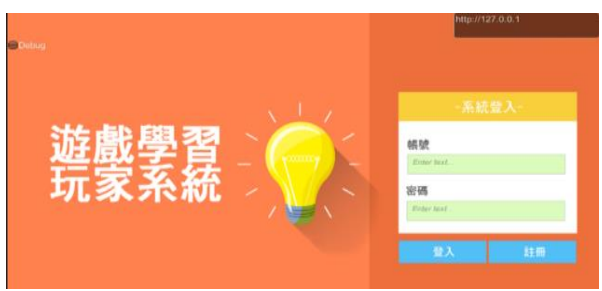

(a)

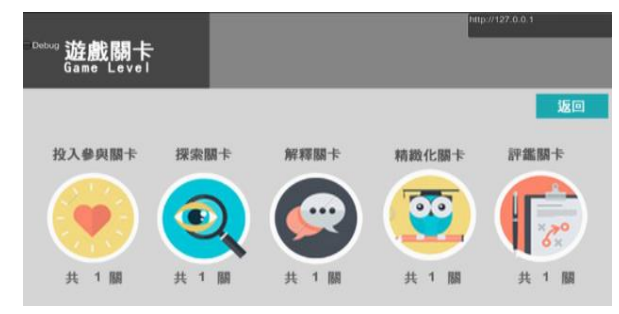

(c)

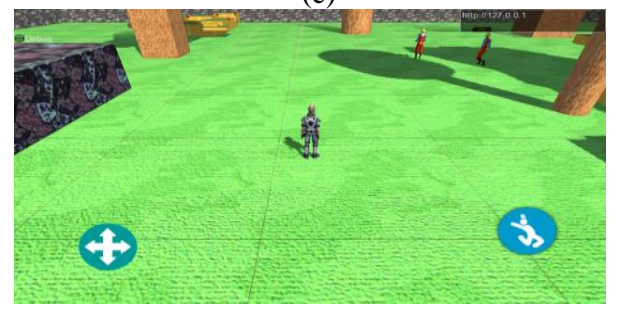

(e)

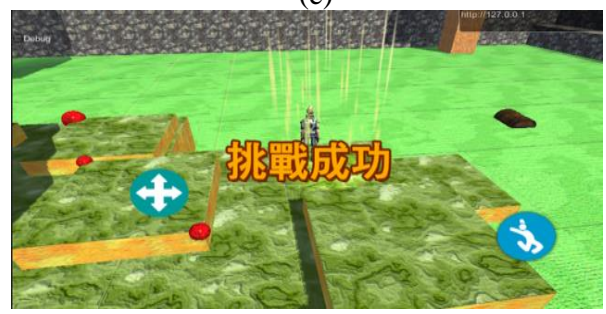

(g)

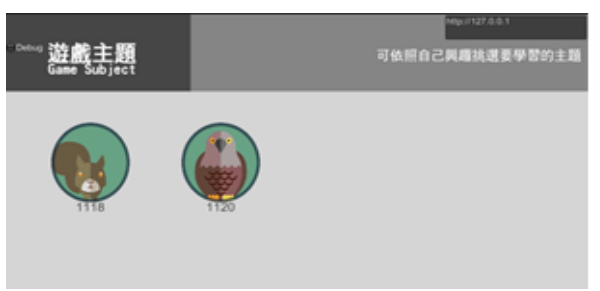

(b)

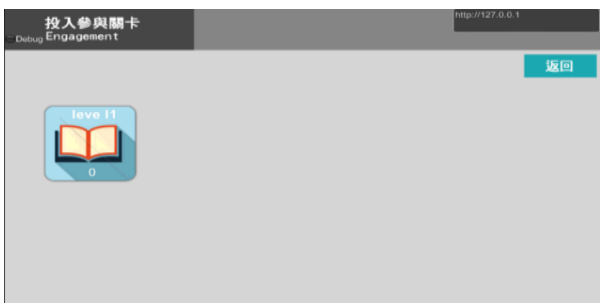

(d)

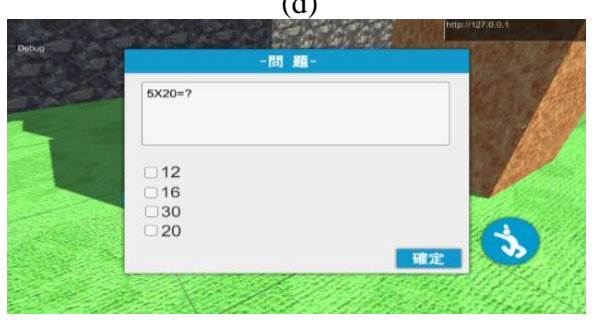

(f)

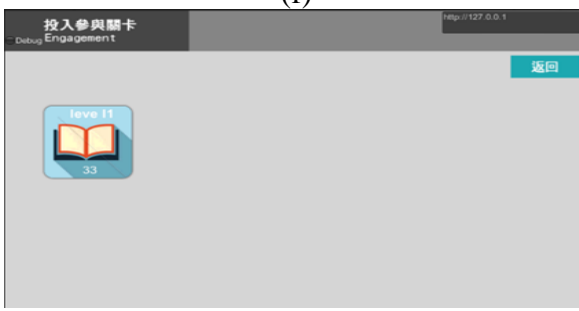

(h)

Fig. 10.(a) To login the CeCAS game-based learning system. (b) To choose a learning subject. (c) To choose one of the 5E learning stages. (d) To enter the learning level. (e) To play the game. (f) To answer the question of NPCs. (g) To complete the level. (h) To record the learning result. 


\section{Conclusion}

Successful education requires high-quality learning contents and creative teaching planning. These requires expertise and skills from experienced educators who ever designed and developed the challenging and realistic cases in different domains. About the proposed educational game script editing system, it mainly aims to provide an efficient and user-friendly way of editing educational game scrip for teachers, including game script editor, scenario writer, asset designer and learning activity planner, a collaborative platform to design learning materials based on the $5 \mathrm{E}$ learning cycle model. The proposed educational game authoring system contributes as below:

1. To integrate Unity 3D game engine and network database technology to fulfil an interactive and collaborative 3D game editor based on the 5E learning cycle.

2. Easier to plan game-based learning themes that conform to the $5 \mathrm{E}$ learning strategy and achieve the gamification of learning contents.

3. Easier to share teaching plans, to share learning resource, and to accumulate and inherit teaching experience.

The prototype of the educational game authoring system is implemented. Currently, MS Windows version and Android version are available. The questionnaire is carried out for system usability. A total of 96 first-year students from University of Technology participated in the questionnaire of this game-based learning system after experienced. The result shows that $83 \%$ of students think educational games are fun and $87 \%$ of students are willing to use the learning system. It is expected to accumulate and share the practical teaching experiences and successful education gamification plans of rich experienced educators using the educational gamification authoring system.

\section{$5 \quad$ Acknowledgment}

This research was supported by the Ministry of Science and Technology of Taiwan, R.O.C., grant number MOST 104-2511-S-230-001 -.

\section{References}

[1] Bybee, R. W. (2009). The BSCS 5E instructional model and 21st century skills: A commissioned paper prepared for a workshop on exploring the intersection of science education and the development of 21 st century skills. The National Academies Board on Science Education, https://doi.org/10.17226/12771

[2] K. Becker (2007). Digital game-based learning once removed: teaching teachers. British Journal of Educational Technology, vol.38, no. 3, pp. 478-488, https://doi.org/10.1111/ j.1467-8535.2007.00711.x

[3] The White House (2013). Preparing a 21st century workforce - science, technology, engineering, and mathematics (STEM) education in the 2014 budget. White House Office of Science and Technology Policy, www.whitehouse.gov/ostp April 10. 
[4] W.Westera, R.J. Nadolski, H.G.K. Hummel, and I.G.J.H.Wopereis (2008). Serious games for higher education: a framework for reducing design complexity. Journal of Computer Assisted Learning, vol.24, no.5, pp.420-432, https://doi.org/10.1111/j.1365-2729.2008. $\underline{00279 . x}$

[5] Hogle, J. G. (1996). Considering games as cognitive tools: In search of effective "Edutainment". University of Georgia Department of Instructional Technology.

[6] Yen-Ru Shi and Ju-Ling Shih (2015). Game Factors and Game-Based Learning Design Model. International Journal of Computer Games Technology, Volume 2015, Article ID 549684, 11 pages, https://doi.org/10.1155/2015/549684

[7] Liu FJ., Tseng CW. (2013). Framework of Supporting Structured Game Script Learning System. In: Chiu D. et al. (eds) Advances in Web-Based Learning - ICWL 2013 Workshops. ICWL 2013. Lecture Notes in Computer Science, vol 8390. Springer, Berlin, Heidelberg, https://doi.org/10.1007/978-3-662-46315-4_17

[8] Chamillard, A.T. (2006). Introductory Game Creation: No Programming Required. SIGCSE '06 Proceedings of the 37th SIGCSE technical symposium on Computer science education, pp. 515-519, https://doi.org/10.1145/1121341.1121502

[9] Jenova Chen (2007). Flow in Games (and Everything Else). Communications of the ACM, April, Vol. 50 No. 4, Pages 31-34.

[10] Van Eck, R.(2008). Building Artificially Intelligent Learning Games. In V. Sugumaran (Ed.), Intelligent Information Technologies: Concepts, Methodologies, Tools, and Applications, pp. 793-825. Hershey, PA: Information Science Reference, https://doi.org/10.4018/ 978-1-59904-941-0.ch048

[11] A. Yessad, J. Labat and F. Kermorvant (2010). SeGAE: A Serious Game Authoring Environment. 10th IEEE International Conference on Advanced Learning Technologies, Sousse, Tunisia, pp. 538-540, https://doi.org/10.1109/icalt.2010.153

[12] Introduction to Asset Bundles, https://learn.unity.com/tutorial/introduction-to-assetbundles. [Accessed May 03, 2021]

[13] Abdulaziz Alsubhi, M., Sahari, N., \& Tengku Wook, T. (2020). A Conceptual Engagement Framework for Gamified E-Learning Platform Activities. International Journal Of Emerging Technologies In Learning (IJET), 15(22), pp. 4-23, https://doi.org/10.3991/ijet.v15i22. 15443

[14] Silva, J., \& Silveira, I. (2020). A Systematic Review on Open Educational Games for Programming Learning and Teaching. International Journal Of Emerging Technologies In Learning (IJET), 15(09), pp. 156-172, https://doi.org/10.3991/ijet.v15i09.12437

[15] Yamani, H. (2021). A Conceptual Framework for Integrating Gamification in eLearning Systems Based on Instructional Design Model. International Journal Of Emerging Technologies In Learning (IJET), 16(04), pp. 14-33, https://doi.org/10.3991/ijet.v16i04.15693

\section{$7 \quad$ Authors}

Feng-Jung Liu received the M.S. and the Ph.D. degrees in Computer Science and Engineering from the National Sun Yat-Sen University, Kaohsiung City, Taiwan, in 1994 and in 2005 respectively. He is currently an Associate Professor with the Department of Digital Multimedia Design, Cheng-Shiu University, Kaohsiung City, Taiwan. His research interest includes the development of web technology, VR/AR content development and the game-based learning. 
Chia-Mei Lu is currently an Associate Professor with the Department of Digital Multimedia Design, Cheng-Shiu University, Kaohsiung City, Taiwan. His main research areas are digital system design, digital learning and interactive media design. The current research publications are mainly in digital media and learning psychology applications. Future research focuses on STEAM and digital media, and applies to learning applications.

Article submitted 2021-05-18. Resubmitted 2021-06-19. Final acceptance 2021-06-22. Final version published as submitted by the authors. 